\title{
TEMAS DE POLÍTICA INTERNACIONAL PARA HISTORIADORES: A CRISE do GOlFo PÉrSICO EM 1991
}

João Fábio Bertonha*

Resumo: A crise do Kuwait e a Guerra do golfo em 1990 e 1991 não só representou o primeiro grande conflito internacional pós Guerra Fria como se destacou por ser, talvez, o conflito que mais destaque teve na mídia. Analisar e estudar o dito acontecimento de furma histórica e crítica é o objetivo desse texto.

Unitermos: guerra; Iraque; Kuwait; oriente médio; islamismo; petróleo

\section{Introdução}

Gostariamos de iniciar este artigo com algumas explicações a respeito da estrutura argumentativa a ser utilizada, dos objetivos que pretendemos atingir e dos limites que este trabalho apresenta.

Antes de mais nada, os objetivos. Este trabalho tem, por objetivo central, a análise de um acontecimento marcante no panorama internacional recente (A Guerra do Golfo), buscando basicamente levantar alguns dados históricos que ajudem a explicar e compreender o dito acontecimento e suas implicações. Entendemos ser este exercício de fundamental importância como contraponto a um esforço de grande parte da mídia - especialmente a televisiva - em camuflar o profundo leque de determinações que levaram ao conflito em favor de explicações baseadas na demonização de certos personagens e em outros aspectos superficiais e imediatistas. Nesse sentido, esperamos

\footnotetext{
"Doutorando em História Social - UNICAMP- Campinas/SP.
} 
BERTONHA, J.P. Temas de politica internacional.

que esse pequeno artigo possa colaborar para o aprofundamento de nossos conhecimentos e para a criação de um debate sobre o tema.

Postos os objetivos, convém ressaltar nossos limites. $\mathrm{O}$ assunto que nós vamos abordar parece ser, conforme vimos, bastante imediato $\mathrm{e}$ com uma explicação simples (um homem ficou louco, invadiu um pais e causou toda aquela confusão), mas isso não é verdade. A compreensão dessa crise internacional que pipocou no Kuwait e que ainda hoje nos influencia exige o estudo de diversos aspectos da história da região desde séculos atrás ( $O$ surgimento e as divisões do Islã, a colonização do Oriente Médio pelos europeus, os equilibrios geopolíticos no pós II Guerra, etc). Nós tentaremos fazer este estudo. Dada, porém, a necessidade de se manter o texto num tamanho razoável, teremos que fazer uma abordagem mais superficial e restrita do que seria realmente necessário. Este é um limite que tem que ficar claro para o leitor, o qual convidamos, de qualquer forma, para um mergulho na história recente do Oriente Médio.

\section{A - Irã (1953-1979)}

Antes de mais nada, gostariamos de ressaltar que não estamos fugindo de nosso assunto central - Iraque e Kuwait - ao abordarmos o Irã. Como veremos logo, os acontecimentos do Irã em 1979 serão determinantes para entendermos a crise do Golfo.

O Irã é uma nação muçulmana xiita (não árabe) que desde os anos 20 vêm sofrendo um processo de ocidentalização lenta. Esse processo será acelerado no govemo do Xá Reza Pahlevi (1953-1979), o que fez vir à tona uma série de contradições e problemas intemos (riqueza e pobreza, religião e modernidade tipo ocidental) da sociedade iraniana: um grande descontentamento surgiu contra o regime do Xá, descontentamento este que foi canalizado pelos religiosos islâmicos. $\mathrm{O}$ Xá reagiu com violência extrema, mas ela foi insuficiente para sufocar a revolta da maior parte da população com a violação das tradiçöes 
BERTONHA, J.P. Temas de politica internacional.

religiosas e a desigualdade social. Em 1979, o Xá cai e o líder dos religiosos, Khomeini, assume o poder ${ }^{1}$.

Implanta-se, então, um sistema onde religião e Estado se fundem quase que completamente: as leis do Corão são as leis nacionais. Um estado integrista surge, pois, do regime do Xá. Alteram-se todos os equilíbrios do Oriente Médio.

\section{B - Iraque, Kuwait e Arábia Sandita (1970-1990)}

Já vimos como o Irã evoluiu de uma ditadura (a do Xá) para uma república islâmica. A combinação de religião e ditadura não é, porém, exclusiva do Irã. Arábia Saudita, Iraque e Kuwait também seguem, em diferentes gradações, este padrão, como veremos agora.

Em primeiro lugar, a Arábia Saudita e o Kuwait. Ambos são emirados governados por reis (monarquias teocráticas) e que, como o Irã, viveram, graças aos recursos do petróleo, um forte processo de modernização nas últimas décadas. Os religiosos, porém, foram cooptados pelas casas reais reinantes nesses paises, o que deu estabilidade política, mas sem dúvida não uma democracia no estilo ocidental, a esses paises.

Já o Iraque (Draper, 1992) segue um padrão diferente. A monarquia teocrática aos moldes da Arábia Saudita e Kuwait foi derrubada em 1958, sendo sucedida por diversos regimes militares até 1968, quando o partido Baas (ou Baath) assume o poder. Como lider de uma das fações do Baas, Saddan Hussein assumiu o poder em 1979, num golpe de estado, e está no poder desde então.

Este Estado que Saddan Hussein implantou a partir de 1979 se diferencia ainda mais das monarquias teocráticas do Golfo. Era um estado leigo (mas que respeitava as tradiçães muçulmanas) e sem duvida alguma, com caracteristicas ditatoriais. De fato, o regime iraquiano se caracterizava pelo esforço de controle de toda a vida social através do partido único, da polícia secreta e da eliminação

- Sobre a revolução iraniana, a bibliografia brasileira é bastante pobre. Ver Carlos (1979), Febrot (1980), Gordon (1987) E Vercellin (1980).

HISTÓRIA \& ENSINO, Londrina, 02: 11]-126, 1996 
BERTONHA, J.P. Temas de poliffa internacional.

sistemática de seus oponentes. Esse uso da força era e é a base do poder de Hussein, mas tem-se que admitir que o ditador contava com o apoio de parcela expressiva da população do país. Isso porque ele combinava, e combina, as medidas violentas com forte propaganda e com medidas efetivamente populares (alfabetização, previdência, redução das desigualdades sociais, etc). Essa combinação de populismo, paternalismo e truculência deu à Saddan Hussein um controle quase que absoluto do Iraque; controle este que, com variaçóes devido à guerra, prossegue até hoje.

A revolução islâmica do Irã e o regime de Saddan Hussein foram postos em contato em um conflito que ensangüentou o Oriente Médio por vários anos: a Guerra Irã-Iraque, que veremos agora.

\section{C - Guerra Irã-Iraque (1980-1988)}

A guerra entre o Irã e o Iraque se iniciou em 22/09/1980, quando as tropas iraquianas invadiram o Irã. Os dois países tinham rivalidade territorial e política de longos anos, rivalidade esta que foi ampliada ainda mais com o advento da Revolução Islầmica no Irã. Ao invadir o Irã, Saddan Hussein esperava atingir certos objetivos nacionais imediatos: destruir a ameaça nascente do xiismo e conseguir áreas produtoras de petróleo para ampliar seus recursos. Além disso, ele procurava o prestigio militar necessário para se aproximar daquele que consideramos um verdadeiro objetivo nacional permanente do Iraque: a liderança do mundo árabe (cargo vago desde a morte de Nasser no Egito em 1970).

Dessa forma, Hussein estava - ou ao menos acreditamos que estava- consciente de sua incapacidade militar para conquistar o enorme Irã, mas acreditava poder se aproveitar da fraqueza militar momentânea e inédita do inimigo - devido às deserções e expurgos nas Forças Armadas e ao isolamento mundial pós-Revolução - para triunfar e obter concessões. $O$ jogo de Hussein era perfeito: $O$ Irã não agüentaria, devido à sua fraqueza pós revolucionária, o ataque iraquiano e faria concessões suficientes para fazer do Iraque a grande 
BERTONHA, J.P. Temas de politica internacional.

potência do Golfo, lider do mundo árabe e, de quebra, um pais mais rico em petróleo e com seus xiitas controlados.

Esse plano perfeito de Hussein falhou devido a um pequeno detalhe: O Irã resistiu. É fato que ele estava enfraquecido, mas, com a união nacional detonada pela guerra e o uso de massas de mártires, o Irã repeliu as ofensivas iniciais do Iraque e, desde 1982, ameaçou contra-atacar para Bagdá. A partir dai, a guerra ficou num impasse em terra (superioridade numérica do Irã contrabalançada pela superioridade em armas do Iraque) enquanto os dois lados tentavam destruir a economia do inimigo via ataques à exportação de petróleo. Nesse ritmo - batalhas ferozes mas não decisivas no deserto conjugados a ataques de asfixia econômica - a guerra prosseguiu por anos a fío. Saddan Hussein, depois de ver o erro que havia cometido, tentou obter a paz, mas o Irã , desejoso de aproveitar a chance para expandir a Revolução Islâmica, sempre recusava. Só quando a pressão de uma frota americana e de vitórias iraquianas se conjugou com a doença de Khomeini (com a conseqüente ascensão dos pragmáticos moderados, interessados em terminar a guerra para evitar o crescente descontentamento entre os iranianos) é que o Irã aceitou negociar e a paz foi feita, em 1988.

Ainda sobre esta guerra, um ponto deve ser destacado para que possamos compreender adequadamente a crise do Kuwait, a qual virá em seguida: a questão dos apoios aos beligerantes durante o conflito.

Logo que se percebeu que o Irã não ia capitular e que, pelo contrário, ele ameaçava conquistar o Iraque, as grandes potências se coligaram numa aliança contra o Irã. Este ficou praticamente isolado (abastecendo-se principalmente via contrabando e comércio clandestino de armas), enfrentando um Iraque abastecido de armas pela URSS velha aliada de Bagdá - e Europa, com apoio monetário (dezenas de bilhões de dólares) dos países árabes e que contava com informações e, quando foi necessário, apoio naval, dos EUA.

É verdade que tanto os emirados árabes quanto os EUA não tinham muita simpatia pelo Iraque (desprezo pela modernidade iraquiana e seqüelas do apoio americano a Israel, respectivamente), mas o medo que uma onda revolucionária islâmica vinda do Irã contagiasse o 
BERTONHA, J.P. Temas de politica internacional.

Oriente Médio e derrubasse as dinastias reinantes nos emirados produtores de petróleo fez com que quaisquer preocupações de ordem moral ou imediatista fossem esquecidas frente ao perigo mator. Foi esse apoio que ajudou Hussein a resistir ao Irã, formar o famoso exército de um milhão de homens de que nós tanto ouvimos falar em 1990/91 e mesmo a se manter no poder: tanto árabes quanto americanos e europeus nunca moveram um músculo sequer para ajudar os oposicionistas ao regime, dado que todos achavam que um homem forte em Bagdá era o ideal a fim de conter o Irã (Miller, 1990). Com o auxilio das grandes potências, assim, a guerra prosseguiu por longos anos...

\section{D - Situação do Irã e do Iraque (1988-1990)}

Tanto Irã quanto Iraque estavam virtualmente exaustos quando a paz foi assinada, tendo ambos por tarefa fundamental a reconstrução de suas economias e sociedades. Mas se a doença - exaustão causada pela guerra - era a mesma, a receita para recuperação variou muito e isto terá um significado todo especial para a crise do Kuwait.

O Irã gastou 220 bilhões de dólares para manter seu esforço de guerra, na qual ele teve, além disso, $300 \mathrm{mil}$ mortos e $600 \mathrm{mil}$ mutilados. A necessidade de reconstruir uma economia devastada fez o Irã se moderar no período 88/90. Essa moderação não significa que o regime iraniano tenha perdido seus componentes autoritários de uma hora para outra, mas que uma tática de emergência foi implantada para impedir que o país afundasse. Com isso, o pais dos aiatolás tomou-se um pouco mais comedido, em termos de relações internacionais, transferindo o grosso das energias para a reconstrução nacional

O Iraque também estava esgotado (180 bilhões de dólares gastos, 200 mil mortos e 400 mil mutilados), mas a sua situação econômica era ainda pior que a do Irã devido a um agravante, a dívida externa. 
BERTONHA, J.P. Temas de política internacional.

O Iraque devia, em 1990, 90 bilhões de dólares que haviam sido usados durante a guerra e isso era preocupante para o país. ${ }^{2}$ Como achar recursos para rolar essa divida, reconstruir o pais e manter o poder bélico (aspecto que Hussein não podia descuidar, sob pena de abandonar seus sonhos de liderança do mundo árabe)? Esse será o estopim da invasão do Kuwait.

\section{E - A Invasão do Kuwait}

Pudemos ver, assim, que a situação do Iraque não era nada boa. Saddan Hussein teve sua atenção desviada, então, para o pequeno Kuwait. Era seu principal credor e estava com os cofres repletos dos dólares que ele necessitava. Com um governo títere lá (a decisão de anexá-lo veio depois), poder-se-iam resolver todos os problemas imediatos do Iraque (fazendo os preços do petróleo subirem, carreando os recursos do vizinho para si e obtendo o perdão da divida) e, de quebra, podia ser melhorada a posição estratégica do pais, resolvendo velhas pendências históricas e geopolíticas (Draper, 1992). Porque não ocupar o vizinho?

Pensando nisso, Saddan Hussein parece ter chegado à conclusão de que uma conquista do Kuwait não geraria uma grande reação mundial. Primeiro, porque ele era aliado de quase todos os países ocidentais e árabes e segundo, porque ninguém ousaria enfrentá-lo. Mesmo assim, ele sondou Washington sobre a possivel reação americana, ficando aparentemente convencido ${ }^{3}$ de que os EUA haviam dado sinal verde. Com isso, a invasão se consumou em 2/8/1990.

Um último ponto. Alguns analistas (Taheri, 1990) têm colocado que outros fatores - a necessidade de uma vitória militar para evitar uma crise política no interior do Iraque e manter Bagdá e o Baas como eixos políticos e ideológicos do mundo árabe - também teriam

- Os dados sobre ambos os países se originam de "Um balanço devastador".in: Jornal da Tarde, São Paulo, 18/8/1988

- Levando-se em conta que as relaçôes EUA X Kuwait não eram as melhores nos anos 80, sua suposição não era absurda. Vide DRAPER (1992b).

HISTÓRIA \& ENSINO, Londrina, 02: 111-126, 1996 
BERTONHA, J.P. Temas de politica internacional.

estimulado Saddan Hussein a invadir o Kuwait e que as determinações imediatas políticas e econômicas citadas acima foram superestimadas pelos analistas.

Essa hipótese é, a nosso ver, perfeitamente plausível. De fato, nos parecer estranha a rapidez com que o Iraque invadiu o Kuwait e o pouco que Hussein negociou com seus credores árabes antes de mover os tanques. A existência de uma necessidade politica para essa invasão, de forma a conjurar problemas intemos e manter a imagem extema nos ajudaria a entender essa pressa. Ainda assim, entendemos que o nosso conhecimento sobre o fluxo de decisões e acontecimentos que acabou levando à invasão é ainda muito fragmentado para que possamos ter conclusões definitivas. $\mathrm{O}$ que nos parece mais provável é que Saddan Hussein tenha se visto diante de uma situação em que necessitava de certos elementos para manter seu poder (recursos monetários, prestigio militar, etc), elementos estes que a invasão do Kuwait fomeceria, aparentemente, a custo zero. Porque não arriscar?

\section{F - Reação Mundial}

Hussein jogava suas esperanças de vitória numa baixa reação mundial à invasão. Porque alguém reagiria se todo o mundo era seu aliado e ele tinha apoio americano? Mais uma vez, porém, Saddan Hussein se equivocou. Ele se esqueceu que o término da guerra IrãIraque diminuia o apoio internacional a seu regime e que o fim da Guerra Fria não fomecia mais clima para intervenções e anexações ao velho estilo. A reação mundial foi, portanto, bastante dura na condenação à conquista, sendo negado à ele o fundamental reconhecimento internacional ao regime títere do Kuwait.

Essa condenação mais forte não estava nos planos do Iraque, mas apenas um pais - desde à decadência da URSS - tinha poder e vontade de usar esse poder para obrigar o Iraque a recuar: os EUA. Era em Washington que se decidiria a crise. E, para infelicidade de Hussein, os EUA decidiram não aceitar a agressão e reagir. A tensão iria se iniciar.

Nesse ponto, abre-se a grande pergunta: Por que os EUA resolveram lutar pelo Kuwait? $O$ discurso oficial diz que os americanos 
BERTONHA, J.P. Temas de politica intemacional.

foram à guerra para defender a justiça e a liberdade contra um tirano opressor. Isso não convence. Os Estados Unidos já apoiaram inúmeras invasões pelo planeta e, na própria luta para vencer o Iraque, silenciaram frente à repressão soviética na Lituânia, à israelense contra os palestinos, etc. Mais ainda, eles se aliaram à Síria, que é uma ditadura tão brutal (vide o massacre de Hama - 1982) e expansionista (Libano) quanto o Iraque. Claro que isto não inocenta Hussein - que é ditador, genocida e que cometeu um ato de pura pirataria -, mas propor que a intervenção americana foi devida ao amor pela liberdade é fazer o jogo americano e esquecer que, em relações internacionais, não se coloca a questão moral: apenas os interesses contam.

Então, o que teria levado os EUA a enfrentar o Iraque? $\mathrm{Na}$ realidade, nós ainda não temos mais do que hipóteses (Futuras pesquisas serão necessárias para determinar ao certo), mas tudo leva a crer que foram preocupações de ordem econômica e estratégica que levaram à intervenção. Washington não podia permitir que alguém como Hussein controlasse - tanto de forma direta como indiretamente, via intimidação dos emirados do Golfo - parte tão expressiva das reservas mundiais de petróleo ; que o equilibrio estratégico regional fosse alterado - não esqueçamos que a visão de segurança nacional dos EUA tem caráter mundial e implica em estabilidade por todo o mundo (Myamoto, 1991) - e nem que fosse aberto o precedente de uma nação pequena desafiar impunemente a ordem internacional. Por tudo isso, os EUA se voltaram contra Bagdá.

Ainda temerosos ${ }^{4}$, mas decididos a reagir, os EUA mobilizaram seus aliados árabes e europeus e conseguiram que a enfraquecida URSS permanecesse neutra e aprovasse o manto jurídico da ONU para a ação americana. Sem essa neutralidade soviética, as opções de

- Um dos temores americanos era o da sublevação das massas árabes contra a intervenção ocidental. Vide, sobre isso, "Revelações da guerra - Os bastidores do conflito do Golfo" in Isto $\dot{e}, 13 / 3 / 1991$ 
BERTONHA, J.P. Temas de política internacional.

Washington seriam extremamente reduzidas e ela deve, assim, ser destacada $^{3}$

Um ponto, contudo, merece destaque na ação americana. Relendo os jomais de agosto e setembro de 1990 , nos fica a forte impressão de que a reação inicial de Washington não cogitava do uso das armas, confiando mais na diplomacia e na pressão econômica. Claro que a opção militar sempre esteve presente (Nos recordemos das palavras de Raymond Aron - (Aron, 1982) - , para quem a distinção entre estratégia e diplomacia é relativa e flexivel, pois ambas são aspectos complementares da política e podem ser utilizadas conforme a necessidade), mas é possivel até que os EUA não tivessem reagido com tanta ênfase se soubessem até onde o jogo iria. Nos parece, assim, que a própria crise teve uma dinâmica que levou à crescente radicalização e, por fim, à guerra. É o que veremos, brevemente, agora.

\section{G - Dinâmica da Crise}

A tática inicial de Washington foi cercar o Iraque militarmente (impedindo-o de avançar para a Arábia Saudita e pressionando-o) e deixar que $o$ isolamento diplomático e o torniquete econômico (aprovados pela ONU e agora possiveis num mundo pós Guerra Fria) obrigassem Saddan a recuar.

5

- Nesse ponto, tomam-se interessantes as colocaçôes de Ronald Sardenberg (Sardenberg, 1982). Ele mostra como a análise das relações e acontecimentos intemacionais não deve se limitar ao plano da ação e reação dos Estados. Há um outro aspecto que deve ser considerado: o sistema intemacional, o qual deixa claro a cada ator o que ele pode ou não fazer em determinado momento.

Isso se encaixa nesse momento estudado, no qual o novo sistema internacional em formação permite uma aliança russo-americana para destruir um foco de perigo no Oriente Médio. Se a mesma situação tivesse ocorrido na vigência do modo de organização do sistema internacional anterior (Bipolaridade com rivalidade), é provável que a URSS anulasse as ações americanas e todo o poder de Washington seria, assim, inútil.

O próprio Sardenberg, em um outro texto (Sardenberg, 1989), dá outras informaçôes sobre como a nova dètente aumentou o grau de liberdade das superpotências, e em especial dos EUA, no mundo. 
BERTONHA, J.P. Temas de politica internacional.

Essa tática malogrou, no entanto, devido a alguns fatores. $O$ bloqueio econômico começou a minar as forças do Iraque, mas ia demorar para pô-lo de joelhos, enquanto a ameaça de ação militar não intimidou - ao contrário do que se esperava - Hussein. É provável que a continuidade do bloqueio acabasse por dernibar o Iraque, mas a Casa Branca não podia esperar muito. Os soldados que cercavam o Iraque não podiam ficar anos estacionados no deserto, a coalizão mundial poderia afrouxar com o tempo e a tensão da crise (afetando a economia mundial) não podia continuar. Era fundamental obrigar o Iraque a sair rápido do Kuwait.

Para fazer isso, os EUA resolveram aumentar a pressão contra o Iraque. Com o beneplácito da ONU e a neutralidade soviética, montouse uma enorme máquina de guerra na região e ameaçou-se (apesar do temor das baixas e da reação da opinião pública) usá-la contra o Iraque. Em novembro, mais pressão: a ONU dá até $15 / 1$ para a desocupação do Kuwait. O prestigio americano estava agora em jogo e Washington se engajava num nivel que talvez não tenha pretendido no início.

O Iraque suportou essa pressão sem esmorecer. Alternando moderação (liberdade dos reféns, por exemplo) com belicismo (anexação total do Kuwait) e aproveitando-se da desconfiança árabe frente aos ocidentais e da questão dos palestinos (para os quais o Iraque nunca deu importância, mas que constituiam uma ferida muito sensivel e que o Ocidente nunca soube tratar), Saddan Hussein, numa prova admirável de controle de seus movimentos no tabuleiro do poder, soube agüentar firme.

Resta agora perguntar: Por que essa intransigência de parte à parte? Por que ninguém recua nem um centímetro? $\dot{A}$ parte aquelas considerações que levaram à invasão e à reação americana e que já vimos, tudo leva a crer que entra ai a própria dinâmica da crise, para o entendimento da qual as reflexões de Karl Deutsch (Deutsch, 1982) sobre os jogos e lutas revelam-se fundamentais. A nosso ver, os atores mantiveram, por toda a crise, um controle extremamente racional de seus movimentos no tabuleiro (Para usar a terminologia de Deutsch, entendemos que raramente houveram lutas na crise do Golfo, mas 
BERTONHA, J.P. Temas de polifica internacional.

apenas jogos) com opções, expectativas e altemativas que se confrontaram com as equivalentes do adversário. Sendo assim, um compromisso teria sido, ao menos em termos teóricos, possivel.

O problema é que a crise do Golfo logo se configurou, para continuarmos com a terminologia de Deutsch, num jogo de soma zero. Ambos os lados tinham investido demais e não podiam ceder nada ao inimigo, sob pena dele se tomar vencedor moral. Deixar Hussein sair com algo significaria perda de prestigio e de credibilidade mundial (e nós sabemos como esses fatores são importantes para um Estado nas relações intemacionais) dos EUA e fortalecimento inadmissível do Iraque. Recuar sem nenhuma compensação significaria um suicídio político para Hussein e o fim de seus sonhos de ser lider árabe. Tanto para Washington como para Bagdá, era melhor manter o jogo até o fim, com um lado testando a determinação do outro e, se necessário, ir à guerra. Com os dois lados assim rígidos em suas políticas, não é espantoso que a crise tenha se convertido em guerra, a qual se iniciou em 16 de janeiro de 1991 .

\section{H - Guerra}

A guerra se iniciou com pouco mais de um mês de intensa atividade aérea. Os EUA e Aliados fizeram cerca de 100 mil ataques aéreos e despejaram cerca de 1 milhão de toneladas de bombas sobre o Iraque. Esse enorme volume de fogo foi dirigido contra alvos militares e estratégicos do Iraque: tropas, usinas de armas químicas e nucleares, alvos econômicos, etc. Com estes ataques, os EUA tencionavam forçar a retirada iraquiana e também cumprir o objetivo (que foi se desenvolvendo no decorrer da crise) de eliminar as fontes de poder militar de Saddan Hussein.

O Iraque suportou sem recuar esse ataque e, dentro do possivel, reagiu com ataques à Arábia Saudita e Israel. Já tendo perdido a primeira aposta do seu jogo (a de que os EUA não teriam coragem de entrar em guerra), Saddan Hussein alterou seus movimentos no tabuleiro. Ele tinha consciência - ou ao menos acreditamos que ele tinha - de que não podia vencer o colosso militar aliado. Tendo essa 
BERTONHA, J.P. Temas de politica internacional.

consciência, seu objetivo passou a não ser mais ganhar, mas não perder (Aron, 1982). Sua tática passou a ser poupar forças e tentar prolongar e expandir a guerra, de forma a causar ebulição nas massas árabes, diminuir o apoio da população ocidental à guerra e conseguir ganhos políticos (pela resistência) interna e externamente.

Em 16/2, quando a guerra terrestre parecia inevitável (já que o Iraque não recuava apenas pelo ataque aéreo). Saddan Hussein fez uma proposta de paz. Tal proposta era realmente inaceitável pelos Aliados (eram mais os termos de um vencedor que os de um pais que estava sendo dizimado pelo ar), mas, nela, o Iraque aceitava sair do Kuwait. Essa concessão parece indicar que Saddan Hussein havia atingido o limite de sua aposta: já tendo obtido um certo volume de vantagens políticas (o fato de ter resistido por um mês à uma formidável coalizão The dava uma reserva de prestigio para uso interno e extemo), poderia agora negociar e recuar. A aceitação de um plano de paz da URSS logo em seguida também confirma isso.

O governo Bush, porém, não aceitou este plano e utilizou todos os argumentos possiveis para justificar o ataque por terra. Por que? Novamente, por razões politicas. Primeiro, porque se queria negar à URSS um papel de destaque no Oriente Médio (o que ela teria se o plano fosse aceito) e segundo, porque não se cogitava em deixar Hussein sair do Kuwait sem ser pisado, humilhado e destituido de força militar. Era fundamental demonstrar, sem sombra de dúvida, quem havia ganho (para destruir de vez aquele foco de perigo) e impedir Israel de revidar - o que ele faria sem dúvida se Hussein continuasse no poder e com grande força militar.

Com isso, o ataque por terra se iniciou em 23/2/1991. Ao contrário do que se esperava, o Exército iraquiano pouco resistiu. Usando ataques aéreos maciços (destruindo a rede de suprimentos, o C3 e o material pesado do inimigo), armas modernas e ataques táticos intensos e profundos, as tropas americanas esmagaram os iraquianos - cujo poder militar foi efetivamente, superestimado ${ }^{6}$, ocuparam o Kuwait e fincaram o pé no Sul do Iraque. Poderiam até ter entrado em Bagdá,

- Vide "segredos de guerra" in $V E J / A$, São Paulo, 20/3/1991 e DRAPER (1992b)

HISTÓRIA \& ENSINO, Londrina, 02: 111-126, 1996 
BERTONHA, J.P. Temas de politica internacional.

mas o medo de efeitos políticos indesejados (Richards, 1993) fez o comando aliado conter seus soldados. A mesma política que conduziu as decisões na crise comandou a concepção da própria batalha e o seu final. Mais uma vez, se confirma que a guerra não segue - ao menos não na maioria dos casos - uma lógica interna e que ela está intimamente ligada com a política ${ }^{?}$

\section{I - A Crise do Golfo e as Relaçôes Internacionais}

A Guerra do Golfo abalou bastante os equilibrios geopoliticos e estratégicos do Oriente Médio: os EUA adquiriram maior influência (apesar da permanência de Hussein no poder no lraque) na região e Israel está, com a derrota do Iraque, mais seguro que nunca militarmente.

Paralelamente, a destruição do Iraque provocou um crescimento do poder iraniano (Ironia: a grande tática ocidental de uma década: armar o Iraque para deter o Irã - foi anulada pelo próprio poder militar ocidental) e isto - mais a crescente influência dos integristas islâmicos (Pierucci, 1992) pode alterar as relações entre os Estados por todo o Oriente Médio

Já em termos mais gerais, não vemos a crise do Golfo como decisiva para o realinhamento do sistema internacional, dado que diversas das tendências presentes nos últimos tempos - ascensão econômica da Europa/Japão, enfraquecimento relativo do poder da URSS e EUA, fim da Guerra Fria após a ascensão de Gorbachev no Kremlin, etc (Kennedy, 1989) - não foram alteradas.

A nosso ver, a crise serviu mais para alterar diversas perspectivas imediatas e ilusórias que o fim da Guerra Fria gerou, como a da ausência de guerras e do uso do poder militar no novo mundo pós

- Como já ressaltado diversas vezes, o principal autor em que nos baseamos para compreender as relações guerra-política foi Raymond Aron (ARON, 1982). Um artigo muito interessante e que aplica as idéias de Aron no contexto do Golfo também foi útil, porém, para a compreensão dessas relações: Vide CAVAGNARI (1991). 
BERTONHA, J.P. Temas de politica internacional.

guerra fria (FONSECA, 1990). O uso da força bruta pelos EUA e o fracasso da União Européia na Ex-luguslávia devido à sua desunião e baixa capacidade de projeção militar mostram, de fato, que o poder militar perdeu importância mas ainda conta na política internacional do pós guerra fria. Lógico que a crise não militarizou um sistema internacional em mudança que caminhava (e parece ainda caminhar) para uma ênfase no aspecto econômico, mas demonstrou os limites dessa concepção.

Entendemos, portanto, que a crise do Golfo Pérsico de agosto de 1990 a fevereiro de 1991 teve um efeito limitado na reelaboração do sistema internacional (sistema este, aliás, que ninguém ainda sabe ao certo como funcionará). Ela pode ter afetado o equilibrio em termos regionais e imediatos e abalado perspectivas utópicas, mas não causou grande impacto em termos de longo alcance.

\section{Referências Bibliográficas}

ARON, Raymond. 1982. "Estratégia e Diplomacia", em O Estado e as Relaçốes Internacionais, Brasilia, Editora da UnB

CARLOS, Newton Carlos 1979. Irã - A força de um povo e de sua religião, Rio de Janeiro, Expressão e Cultura.

CAVAGNARI, Geraldo Lesbat Filho. 1991. " "A guerra e sua lógica", O Estado de São Paulo, São Paulo, 6/4/1991.

DEUTSCH, Karl 1982. Analise das Relações Internacionais. Brasilia, Editora da UnB.

DRAPER, Theodore. 1992. "A guerra do Golfo reconsiderada". Política Externa, São Paulo, I, 1: 75-84, junho 1992.

1992b. "A verdadeira história da Guerra do Golfo". Politica Exterma, São Paulo, I, 1: 95-115, junho 1992.

FEBROT, Luís Israel. 1980. " "Irã, a terceira insurreição ou o início da revolução?" . Encontros com a Civilização Brasileira, Rio de janeiro, 19:43-72, jan/1980.

FONSECA, Gélson Júnior. 1990. "Aspectos da Multipolaridade Contemporânea (notas preliminares)". Contexto Internacional, 11: 7-32, jan/jun 1990. 
BERTONHA, J.P. Temas de politica internacional.

GORDON, Mathew. 1987. Khomeini. São Paulo, Nova Cultural.

KENNEDY, Paul, 1989. Ascensão e Queda das Grandes Potências Transformação Econômica e Conflito Militar de 1500 a 2000. Rio de Janeiro, Campus.

MILLER, Judith. 1990. Saddan Hussein e a Crise do Golfo. São Paulo, Scritta.

MYAMOTO, Shiguenoli. 1991 Motivações do papel dos Estados Unidos no Mundo. Coleção Primeira Versão 40 Campinas, IFCH/UNICAMP.

PIERUCCI, Antônio F. 1992. . "Fundamentalismo e Integrismo: os nomes e as coisas". Revista USP, 13: 144-156, mar/mai 1992.

RICHARDS, Charles. 1993. "Chefe da CIA conta porque Saddan se manteve". Folha de São Paulo, São Paulo, 10/1/1993

SARDENBERG, Ronaldo, 1982. Estudo das_Relações Internacionais, Brasilia, UnB.

1989. "A Estratificação Internacional nos anos 90", em FONSECA, Gélson Jr e LEÃO, Waldemar Carneiro. Temas de Política Externa Brasileira, Brasilia/São Paulo, IPRI/Ática, 1989.

TAHERI, Amir. 1990.. "Tensão intema determinou ação do Iraque". $O$ Estado de São Paulo, São Paulo, 23/12/1990.

VERCELLIN, Giorgio. 1980. "Notas sobre a revolução iraniana". Encontros com a Civilização Brasileira, 19:19-42, jan/1980. 